\title{
Optimized microwave delivery in dDNP
}

\author{
Albannay, Mohammed M.; M.O. Vinther, Joachim; Capozzi, Andrea; Zhurbenko, Vitaliy; Ardenkjær- \\ Larsen, Jan Henrik
}

Published in:

Journal of Magnetic Resonance

Link to article, DOI:

10.1016/j.jmr.2019.06.004

Publication date:

2019

Document Version

Peer reviewed version

Link back to DTU Orbit

Citation (APA):

Albannay, M. M., M.O. Vinther, J., Capozzi, A., Zhurbenko, V., \& Ardenkjær-Larsen, J. H. (2019). Optimized microwave delivery in dDNP. Journal of Magnetic Resonance, 305, 58-65.

https://doi.org/10.1016/j.jmr.2019.06.004

\section{General rights}

Copyright and moral rights for the publications made accessible in the public portal are retained by the authors and/or other copyright owners and it is a condition of accessing publications that users recognise and abide by the legal requirements associated with these rights.

- Users may download and print one copy of any publication from the public portal for the purpose of private study or research.

- You may not further distribute the material or use it for any profit-making activity or commercial gain

- You may freely distribute the URL identifying the publication in the public portal

If you believe that this document breaches copyright please contact us providing details, and we will remove access to the work immediately and investigate your claim. 


\section{Accepted Manuscript}

Optimized microwave delivery in dDNP

Mohammed M. Albannay, Joachim M.O. Vinther, Andrea Capozzi, Vitaliy

Zhurbenko, Jan Henrik Ardenkjaer-Larsen

PII:

S1090-7807(19)30111-9

DOI:

https://doi.org/10.1016/j.jmr.2019.06.004

Reference:

YJMRE 6500

To appear in:

Journal of Magnetic Resonance

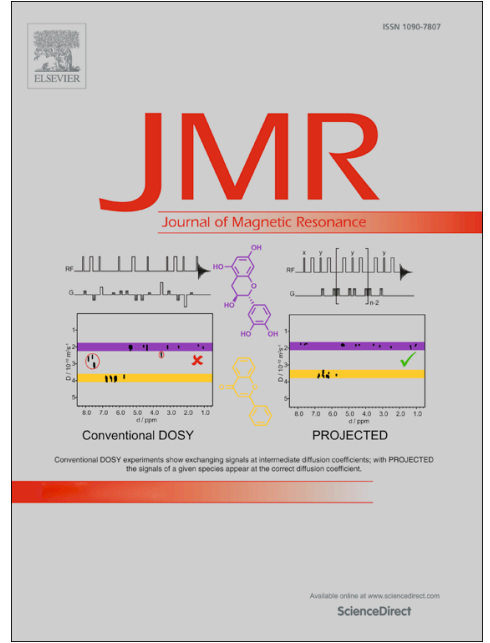

Received Date: $\quad 30$ April 2019

Revised Date: $\quad 9$ June 2019

Accepted Date: $\quad 10$ June 2019

Please cite this article as: M.M. Albannay, J.M.O. Vinther, A. Capozzi, V. Zhurbenko, J. Henrik Ardenkjaer-Larsen, Optimized microwave delivery in dDNP, Journal of Magnetic Resonance (2019), doi: https://doi.org/10.1016/j.jmr. 2019.06.004

This is a PDF file of an unedited manuscript that has been accepted for publication. As a service to our customers we are providing this early version of the manuscript. The manuscript will undergo copyediting, typesetting, and review of the resulting proof before it is published in its final form. Please note that during the production process errors may be discovered which could affect the content, and all legal disclaimers that apply to the journal pertain. 


\section{Optimized microwave delivery in dDNP}

Mohammed M. Albannay ${ }^{1}$, Joachim M. O. Vinther ${ }^{1}$, Andrea Capozzi ${ }^{1}$, Vitaliy Zhurbenko ${ }^{1}$, Jan Henrik Ardenkjaer-Larsen ${ }^{1,2}$

1. Center for Hyperpolarization in Magnetic Resonance, Magnetic Resonance, Department of Health Technology, Technical University of Denmark, Ørsteds Plads, 2800, Kgs. Lyngby, Denmark 2. GE Healthcare, Brøndby, Denmark

Corresponding author:

Jan Henrik Ardenkjaer-Larsen

Technical University of Denmark

Ørsted Plads, bldg. 349, room 126

2800 Kgs Lyngby

Denmark

Keywords

Dissolution-DNP, microwave, electromagnetic simulation, solid-state NMR 


\section{Abstract}

Dissolution dynamic nuclear polarization (dDNP) has permitted the production of highly polarized liquid-state samples enabling real-time imaging of metabolic processes non-invasively in vivo. The desire for higher magnetic resonance sensitivity has led to the development of multiple home-built and commercial dDNP polarizers employing solid-state microwave sources. Providing efficient microwave delivery that avoids unwanted heating of the sample is a crucial step to achieve high nuclear polarization. Consequently, a process is described to reduce waveguide attenuation due to resistive loss thereby doubling the delivered power. A mirror and reflector are designed and tested to increase the microwave field density across the sample volume resulting in a $2.3 \mathrm{~dB}$ increase of delivered power. Thermal considerations with regards to waveguide geometry and dDNP probe design are discussed. A thermal model of the dDNP probe is computed and experimentally verified. 


\section{Introduction}

Dissolution dynamic nuclear polarization (dDNP) has emerged as the leading hyperpolarization technique to address low magnetic resonance sensitivity in the liquid-state. The process relies on unpaired electron spins in paramagnetic molecules that align to an external magnetic field to a much greater extent than nuclear spins, especially at low temperatures $(1-4 \mathrm{~K})$. This alignment is transferable to neighboring nuclei yielding to a significant increase in signal-to-noise ratio. Subsequently, the frozen sample is dissolved by a hot solvent to obtain a hyperpolarized injectable solution.

The introduction of dDNP [1] enabled real-time imaging of metabolic processes non-invasively in vivo [2,3]. The desire for higher magnetic resonance sensitivity has led to the development of multiple home-built and commercial dDNP polarizers [4-6]. The recent rising trend in employing superconducting 'dry magnets' [6,7] with a variable magnetic field $\left(B_{0}\right)$, up to $10.1 \mathrm{~T}$, allows the investigation of DNP physics in different experimental conditions. Accordingly, a broadband microwave solution is required to fulfil DNP needs at different magnetic fields.

To achieve good DNP performance, the microwave field must be strong enough to saturate the electron spins efficiently. Microwave losses become more severe at higher frequency [8], but a brute increase in power is not the solution. Moreover, especially in the case of dry magnets where the cooling efficiency is limited, excessive microwave power will result in sample heating, thus lowering the DNP enhancement [9]. Efficient microwave delivery while maintaining a reasonably low output power is essential when working at high field. Two features are to be improved to achieve this goal. First, to minimize transmission loss to the sample while ensuring high thermal isolation between the low-temperature sample space and room temperature input flange. Second, to maximize the microwave field density across the sample volume, which in most cases measures several wavelengths.

We propose a microwave solution based on a solid-state source and plated stainless-steel waveguide that provides low-loss transmission between the source output and electron spins. In contrast to corrugated waveguides and/or electromagnetic (EM) mode converters, the proposed solution offers a wide operational bandwidth and is capable of servicing a range of magnetic fields. Efficient multipliers append to the source output to extend its operational frequency. Microwaves are confined inside an overmoded, low $Q$ cavity. A mirror and reflector confine the microwave energy within the sample volume to increase the field density across it. We studied two typical dDNP samples with different spectral widths and relaxation times to provide sufficient physical systems to investigate the microwave delivery process. 


\section{Materials and Methods}

\section{Solid-state DNP polarizer}

All experiments were performed on a home-built dDNP polarizer that is described in [1]. The polarizer magnet (Magnex Scientific, Oxford, UK) is charged to 6.7 T. The solid-state microwave source is based on an actively multiplied and amplified Gunn diode oscillator (Quinstar Technology, CA, USA) and a 200X2R4 frequency doubler (VDI, VA, USA). A NI-USB-6525 data acquisition device (National Instruments, TX, USA) controls the microwave source tuning frequency and power attenuation. The source center frequency is $187.8 \mathrm{GHz}$ with a tuning range of $\pm 0.5 \mathrm{GHz}$ and power output up to $58.5 \mathrm{~mW}$. The polarizer has a helium flow variable temperature insert (VTI) capable of reaching a base temperature of $1.20 \mathrm{~K}$. The dDNP probe, depicted in Figure 1 consists of an ISO-F100 flange (Kurt J. Lesker company, PA USA) that accommodates a 790 $\mathrm{mm} 316 \mathrm{~L}$ stainless steel sample tube $(I D=11.8 \pm 0.10 \mathrm{~mm}, \mathrm{OD}=12.7 \pm 0.10 \mathrm{~mm})$ at its center. $A$ $780 \mathrm{~mm} \mathrm{316L}$ stainless steel waveguide couples the output of the microwave source to a cylindrical overmoded copper cavity (ID $=27 \pm 0.1 \mathrm{~mm}$ and $\mathrm{h}=30 \pm 0.1 \mathrm{~mm}$ ) located at the end of the sample tube. The waveguide outlet centers $9 \mathrm{~mm}$ off the cavity center axis, while the sample coil and sample tube centers $1 \mathrm{~mm}$ in the opposing direction. A UT141SS-C-P semi-rigid coaxial cable (JYEBAO Co., Taiwan) couples the sample coil to a spectrometer via a hermetic bulk head SMA connector. The cable outer conductor is made of stainless-steel, while the inner conductor is silver plated copper. Three Allen-Bradley resistors stacked $1 \mathrm{~cm}$ vertically apart and a Cernox CX1030 temperature sensor (Lakeshore Equipment, CA, USA) placed above the cavity measure the level of liquid helium and VTI temperature, respectively via a Fischer connector on the ISOF100 flange. The sample tube extrudes by $3 \mathrm{~cm}$ above the ISO-F100 flange and terminates into a KF-16 flange, forming the sample loading port. A gate valve (VAT, Switzerland) and airlock adapted from the SPINlab polarizer [10] are mounted above the sample loading port.

\section{Microwave delivery}

Waveguide geometry

The optimum waveguide should offer the lowest attenuation possible while limiting the crosssectional area for heat flux conduction between the input flange and sample space. Attenuation due to resistive losses in a rectangular waveguide is defined by [8]:

$$
\alpha_{c}[\mathrm{~dB} / \mathrm{m}]=20 \log _{10}(e) \frac{R_{S}}{a^{3} b \beta k n}\left(2 b \pi^{2}+a^{3} k^{2}\right)
$$


where $a$ and $b$ denote the height and width of the waveguide, intrinsic impedance of the waveguide $\eta=\sqrt{\mu / \epsilon}$, surface resistance $R_{S}=\sqrt{\omega \mu / 2 \sigma}$, wavenumber $k=\omega \sqrt{\mu \epsilon}$, propagation constant $\beta=$ $\sqrt{k^{2}-\left[(m \pi / a)^{2}+(n \pi / b)^{2}\right]}$ for propagation mode $\mathrm{TM}_{n m}$ or $\mathrm{TE}_{n m}, \mu$ : permeability, $\varepsilon$ : permittivity, $\omega$ : angular frequency and $\sigma$ : conductivity.

Alternatively, attenuation to resistive losses in a circular waveguide is expressed as [8]:

$$
\alpha_{c}[\mathrm{~dB} / \mathrm{m}]=20 \log _{10}(e) \frac{R_{S}}{r k \eta \beta}\left[\left(\frac{p_{n m}}{r}\right)^{2}+\frac{k^{2}}{p_{n m}^{2}-1}\right]
$$

where $r$ denote the radius of the waveguide, the root or root derivative Bessel function $p_{n m}$ corresponds to propagation modes $\mathrm{TM}_{n m}$ or $\mathrm{TE}_{n m}$, respectively and propagation constant $\beta=$ $\sqrt{k^{2}-\left(p_{n m} / r\right)^{2}}$. Equations 1 and 2 establish two findings, firstly, an inverse relationship exists between the waveguide attenuation and perimeter, thereby promoting the use of overmoded waveguides for low loss transmission. Secondly, circular waveguides offer a better ratio between attenuation and perimeter than rectangular waveguides as illustrated in Figure 2. When choosing the waveguide size, the upper perimeter limit was established to be where the attenuation rate reduces less than the heat load rate increases, rendering further expansion thermally costly. The lower perimeter limit would be established as the perimeter of a single-mode WR-10 waveguide. As such, a seamless smooth wall 304 stainless-steel tube with a diameter $4.16 \pm 0.20 \mathrm{~mm}$ is employed. The tube is cut to the desired length and vacuum brazed onto a modified UG387 flange to allow installation onto the dDNP probe post plating with an O-ring seal. The fundamental propagation mode is $\mathrm{TE}_{11}\left(p_{11}=1.841\right)$ with a cut-off frequency of $42.26 \mathrm{GHz}$.

\section{Electroplating}

Stainless-steel is a poor conductor both thermally $(16 \mathrm{~W} / \mathrm{mK})$ and electrically $\left(\sigma_{\mathrm{SS}}=1.45 \times 10^{6} \mathrm{~S} / \mathrm{m}\right)$. Electroplating the inner walls of the tube with a few skin depths of copper yields a composite waveguide with the thermal properties of stainless-steel and electrical conductivity of copper $\left(\sigma_{\mathrm{Cu}}=5.8 \times 10^{7} \mathrm{~S} / \mathrm{m}\right)$. Before electroplating, the waveguide is treated using Autosol $\circledast$ metal polish (Dursol-Fabrik Otto Durst, Germany) and a soft brush to reduce surface impurities and surface roughness mechanically. The waveguide is installed in a spring-loaded fixture that provides the required tension to center a cathode wire through the tube. The fluid is drawn through the waveguide using a peristaltic pump (LongerPump BT300-2J, Hebei, P.R. China) with a DG15 pump head specified to displace up to $900 \mathrm{~mL} / \mathrm{min}$ while rotating at $300 \mathrm{RPM}$. Two silicone tubes connect on either end of the fixture and lie in the chemical bath to allow for fluid ingress and 
egress. A detailed list of the 8-step electroplating process is available in the supplementary material and consists of 5 unique actions.

1. Cathodic cleaning: The liberation of gases from the cathode scrubs the inner surface of the waveguide displacing grease and excess polish.

2. Neutralization: Water is pumped through the waveguide to rinse any remnant solvents from the former bath.

3. Acid treatment: Removal of alkaline residuals or tenacious oxide films. The acid treatment also allows for surface roughening which promotes stronger electrodeposit adherence.

4. Nickel plating: The stainless-steel walls are pre-plated with Wood's nickel to form a host layer for the final copper plate.

5. Copper plating: The alkaline copper cyanide bath deposits $0.3 \mu \mathrm{m}$ of copper per $\mathrm{A} / \mathrm{dm}^{2} / \mathrm{min}$. Current flow is limited to $300 \mathrm{~mA}$ as low amperage is favored to reduce surface roughness [11]. The internal waveguide area is $1.02 \mathrm{dm}^{2}$, requiring a minimum plate time of $150 \mathrm{~s}$ to deposit a single skin depth $(215.52 \mathrm{~nm})$ at $94 \mathrm{GHz}$ and room temperature. To account for oxidation or abrasion during post-plate treatment, the plating time is extended to $30 \mathrm{~min}$, depositing approx. 12 skin depths of copper on the inner waveguide walls. Once electroplated, the waveguide surface is treated with metal polish using a soft brush to reduce surface roughness. Subsequently, the waveguide is rinsed with ethanol and dried with helium or nitrogen gas.

\section{Characterizing conductive attenuation}

Waveguide attenuation is verified on the bench using a $200 \mathrm{~mW}, 94 \mathrm{GHz}$ solid-state microwave source based on an actively multiplied and amplified Yttrium iron garnet oscillator. The source frequency is further multiplied using a D175 doubler or T282 tripler (VDI, VA, USA) to perform measurements at 188 and $282 \mathrm{GHz}$, respectively. Two WR10, WR05 or WR03 rectangular to circular transitions (transmission loss of $0.23 \pm 0.02,0.27 \pm 0.03$ and $0.49 \pm 0.04 \mathrm{~dB}$ each corresponding to 94, 188 and $282 \mathrm{GHz}$, respectively) couple the waveguide source (or multiplier) and Erickson PM5 power meter (VDI, Charlottesville, VA, USA). A GuideLock® quick connect (Quantum Microwave, MA, USA) couples the modified UG387 flange to the transition flange to mitigate cocking or misalignment.

\section{Refined microwave scattering in an overmoded cavity}

The sample vial is indirectly irradiated inside the cavity, which measures several tens of wavelengths in dimensions. Attempting to achieve a single mode resonance is unfeasible due to the sample size. However the cavity can be augmented with mirrors, reflectors and/or perturbing 
rods to support a higher microwave field density across the sample volume, as demonstrated in [12-15]. The design of a mirror and reflector were designed using the EM simulation software, CST Microwave Studio (Dassault Systèmes, France). An automatically generated mesh resolution with a minimum cell size of $\lambda / 12$ was initially adopted, but subsequently halved $(\lambda / 24)$ within the regions of the mirror, reflector and sample to improve the accuracy of the time domain solver. The sample volume in the simulation model was increased to $1 \mathrm{~cm}^{3}$ (spherical volume) at the centre of the sample coil to adapt the method to larger samples sizes. Electric sample properties are adopted from [16], where the authors report $\varepsilon_{\mathrm{r}}=3.5 \pm 0.1$ and tan $\delta=0.005 \pm 0.005$ at $140 \mathrm{GHz}$ for a 1 $\mathrm{M}{ }^{13} \mathrm{C}$-urea in a volumetric ratio 6:3:1 $\mathrm{d}_{8}$-glycerol, $\mathrm{D}_{2} \mathrm{O}$ and $\mathrm{H}_{2} \mathrm{O}$ with $10 \mathrm{mM}$ TOTAPOL at $77 \mathrm{~K}$. These values are further supported by [17] where the dielectric properties of glycerol, propylene glycol, ethylene glycol and dimethyl sulphoxide are investigated between 193-293 K at $2.02 \mathrm{GHz}$. It can be concluded that $\varepsilon_{\mathrm{r}}=2-4$, independent of frequency at temperatures $<193 \mathrm{~K}$. A detailed study of sample size, shape and electric properties is outside of the scope of this work but may affect the power density.

\section{Microwave mirror}

To avoid perturbing the homogeneity of the sample coil, the waveguide outlet is restricted from extruding into the cavity. As a result, microwaves scatter upon entry of the cavity leading to a poor field density in the sample region. Fortunately, the sample is encompassed by the Alderman-Grant coil that can be exploited to confine the microwaves in a smaller volume than the cavity. To do so, a mirror needs to reflect incident microwaves into the $87^{\circ}$ coil opening. EM simulations determined an optimum angle of $75^{\circ}$ is required to achieve the desired goal. The mirror was machined from brass and soldered onto the upper cavity flange. It measures $11.7 \pm 0.10 \mathrm{~mm}$ high and extrudes by $5.0 \pm 0.1 \mathrm{~mm}$ towards the sample coil (Figure $3 a$ and $b$ ).

Segmented reflector

Incident microwaves propagate through the coil opening and the sample volume. Some of the microwave power reflect due to change in material properties between the helium medium and sample, but the majority propagate towards the opposing coil opening and back into the cavity. Reflecting the waves at the second coil opening would confine the microwaves within the coil volume and further increase the field density. The reflector is fabricated on a $0.127 \mathrm{~mm}$ thick Rogers RO3003 laminate (Rogers Corporation, AZ, USA) with a dielectric constant $\varepsilon_{\mathrm{r}}=3.00 \mathrm{~mm}$ and single $0.35 \mu \mathrm{m}$ copper cladding. Placing a conductor near the coil will perturb its homogeneity. To mitigate this distortion, a segmented honeycomb geometry is etched on the laminate to minimize the formation of large eddy currents. The reflector dimensions are depicted in Figure $3 \mathrm{c}$ 
and is installed in between the coil former and coil with the segmented conductor situated to cover the coil opening.

\section{Thermal analysis and empirical verification}

Heat flux from the ISO-F100 flange conducts across the probe and dissipates into the helium bath leading to a warmer sample space and increased helium evaporation. Although, other forms of heat loading exist (e.g. radiation) only conduction will be considered due to its significant contribution in steady-state conditions. The dDNP probe is modelled in COMSOL Multiphysics ${ }^{\circledR}$ (COMSOL Inc., Sweden) including thermal conductivity and heat capacity properties of probe material between 4-300 K [18]. The steady-state heat flux deposited into the helium bath is computed by:

$$
Q=\frac{k A \Delta T}{x}
$$

where $k$ denotes thermal conductivity, $A$ cross-sectional area, $\Delta T$ temperature differential between component ends and $x$ the distance between ends.

In steady-state conditions, the needle valve regulates the volume of liquid helium in the VTI. Conducted heat flux across the dDNP probe is quantified via helium consumption from the magnet vessel with and without microwave irradiation for an extended duration of time. Given the two measurements and known power from microwave irradiation, conducted heat flux by the dDNP probe can be determined. The helium vessel monitors the available volume using an E5011 helium sensor (Magnex Scientific, Oxford, UK) that relies on a length of superconductive wire. Polling the helium level causes an excitation current between $80-245 \mathrm{~mA}$ to flow through the wire, which momentarily leads to liquid boiling. Therefore, polling is limited to every $8 \mathrm{~h}$ or when forced.

\section{Sample preparation and experimental procedure}

Microwave delivery is investigated with DNP using stainless-steel (both with and without an augmented cavity) and copper plated waveguides (with augmented cavity). ${ }^{13} \mathrm{C}$ nuclear polarization is measured every $60 \mathrm{~s}$ for $75 \mathrm{~min}$ using a low flip angle pulse $\left(2.5^{\circ}\right)$ via a remotely tuned and matched coil. Experiments are repeated at least three times, for microwave source powers from 5$55 \mathrm{~mW}$ in $10 \mathrm{~mW}$ increments. Additional measurements at 1 and $2.5 \mathrm{~mW}$ are acquired when verifying the copper plated waveguide. Sample space temperature and cryostat pressure values are regulated to $1.20 \pm 0.01 \mathrm{~K}$ and $0.80 \pm 0.05 \mathrm{mbar}$ at the start of every experiment. The irradiation process is evaluated using 2 unique samples:

1. $50 \mu \mathrm{L}$ solution of $14 \mathrm{M}\left[1-{ }^{13} \mathrm{C}\right]$ pyruvic acid with $30 \mathrm{mM}$ trityl (AH111501). 
2. $100 \mu \mathrm{L}$ solution of $4.5 \mathrm{M}\left[1{ }^{-13} \mathrm{C}\right]$ urea dissolved in glycerol- $\mathrm{d}_{8}$ and $\mathrm{D}_{2} \mathrm{O}(50: 50 \mathrm{v} / \mathrm{v})$ with 40 mM TEMPOL (4-hydroxy-2,2,6,6-tetramethylpiperidine-1-oxyl).

The samples are injected into a cylindrical polytetrafluoroethylene (PTFE) threaded vial with a height $35.00 \pm 0.05 \mathrm{~mm}$, inner diameter $4.00 \pm 0.05 \mathrm{~mm}$ and wall thickness $1.00 \pm 0.05 \mathrm{~mm}$ and is sealed by a threaded cap [19]. The co-axial tubing of a fluid path as described in [10] is attached to the cap using a UV-cured adhesive Dymax 215-C (Dymax Corp, CT, USA). The sample vial is flash-frozen in liquid nitrogen to preserve sample homogeneity and purged with gaseous helium via the fluid path to displace the vial atmosphere before loading into the polarizer. A microwave frequency sweep was performed for each sample between 187.85 to $188.15 \mathrm{GHz}$ to identify the maximum DNP enhancement. Once the experiments are completed the build-up of NMR signal intensity is fitted using a mono-exponential function.

\section{$\underline{\text { Results }}$}

\section{Bench measurements and simulations}

Waveguide attenuation is illustrated in Figure 4 for five stainless-steel waveguides measured before and after electroplating. The mean reduction in resistive losses was $2.6 \pm 1.0,2.5 \pm 0.5$ and $3.4 \pm 0.2 \mathrm{~dB}$ at 94,188 and $282 \mathrm{GHz}$, respectively. Ultimately, the waveguide installed in the dDNP probe reduced resistive losses by $3.3,3.2$ and $3.8 \mathrm{~dB}$, respectively.

Installation of the microwave mirror does not perturb the coil magnetic field nor degrade the measured Q-factor. However, the inclusion of the segmented reflector reduced the measured $Q$ factor from 355 to 342 when measured at room temperature. Spatial variation in the linearly polarized magnetic field amplitude, $B_{1}$, across the isometric center of the coil are illustrated in Figure 5 and indicate a $10 \mathrm{~mm}$ diameter-spherical-volume of $95 \%$ homogeneity, which reduces to $8 \mathrm{~mm}$ when augmenting the cavity (mirror and reflector). Simulated time-averaged $\mathrm{H}$-field distributions across the cavity isocenter are shown in Figure 6. It could be noted, less than $-20 \mathrm{~dB}$ of incident microwave power scatters to the walls of the cavity or around the coil opening. Addition of the mirror and reflector raises the average $\mathrm{H}$-field across the spherical sample volume by a factor of 2.85 (corresponding to a $9.1 \mathrm{~dB}$ increase in source power).

\section{DNP measurements}

${ }^{13} \mathrm{C}$ polarization and build-up time constant for $50 \mu \mathrm{L} 14 \mathrm{M}\left[1{ }^{13} \mathrm{C}\right]$ pyruvic acid with $30 \mathrm{mM}$ trityl (AH111501) are illustrated in Figure 7 at varying powers levels. Optimum irradiation frequency is determined to $187.96 \mathrm{GHz}$ for maximum positive polarization. All DNP probe configurations achieved approx. $65 \%$ maximum polarization, requiring at least $2.5 \mathrm{~mW}$ with a copper waveguide, $5 \mathrm{~mW}$ using a stainless-steel waveguide with an augmented cavity and $15 \mathrm{~mW}$ when exclusively 
employing a stainless-steel waveguide. Increasing microwave power beyond $25 \mathrm{~mW}$ causes up to $35 \%$ relative degradation in nuclear polarization when using a copper plated waveguide.

Similarly, up to $10 \%$ reduction is observed when using a stainless-steel waveguide with an augmented cavity for microwave powers exceeding $45 \mathrm{~mW}$. No observable degradation occurs when exclusively using a stainless-steel waveguide. The build-up time reduces with increasing power levels following an inverse relationship. At high power levels with reported polarization loss, build-up time constants reduce linearly due to heating caused by microwave irradiation.

DNP measurements for $100 \mu \mathrm{L} 4.5 \mathrm{M}\left[1^{1-13} \mathrm{C}\right]$ urea in glycerol- $\mathrm{d}_{8}$ and $\mathrm{D}_{2} \mathrm{O}(50: 50 \mathrm{v} / \mathrm{v})$ with $40 \mathrm{mM}$ TEMPOL are illustrated in Figure 8 for varying powers levels. The irradiation frequency is set to $188.06 \mathrm{GHz}$ with $50 \mathrm{MHz}$ modulation at a $1 \mathrm{kHz}$ rate. All microwave configurations achieve approx. $28 \pm 5 \%$ maximum polarization at different power levels. In this case, $5 \mathrm{~mW}$ with a copper waveguide and $10 \mathrm{~mW}$ using a stainless-steel waveguide regardless of cavity augmentation. Increasing microwave power causes up to $5 \%$ reduction in nuclear polarization when using a copper plated waveguide. Build-up time constants decrease following a power law with respect to irradiated power levels. Inclusion of an augmented cavity leads to an approx. 30\% decrease in build-up time while the use of a copper plated waveguide results in approx. $45 \%$ reduction.

\section{Heat load estimation}

Computed heat loads contributed by probe components are listed in Table 1 and total $222.4 \mathrm{~mW}$. It is worth noting that this value is only for relative comparison, since the enthalpy of the cold helium gas and helium conduction is not be accurately accounted for using this simplified thermal model. Experimentally, $5.15 \pm 0.50 \mathrm{~L}$ of liquid helium were consumed to cool the sample space to $1.4 \mathrm{~K}$ in a span of $24 \mathrm{~h}$. For the same duration and with an average microwave irradiation of $27.1 \mathrm{~mW}$ via a copper plated waveguide consume $5.65 \pm 0.50$ L. Given all irradiated microwave energy is converted into heat, the following ratio can represent the total volume of boiled helium,

$$
(P+Q) t / \mathrm{V}
$$

where, $V$ denotes consumed helium volume, $t$ experiment duration and $P$ microwave power and $Q$ the conducted heat flux. Substituting measured data into (4) yields,

$$
\begin{gathered}
(27.1[\mathrm{~mW}]+Q[\mathrm{~mW}]) 86400[s] / 5.85 \pm 0.50[L] \\
(0+Q[\mathrm{~mW}]) 86400[s] / 5.15 \pm 0.50[L]
\end{gathered}
$$


Equating (5) and (6) identifies the heat flux conducted by the dDNP probe, which amounts to 195 $\pm 20 \mathrm{~mW}$. The experimentally equated heat load value is in good agreement to the theoretical value of $222.4 \mathrm{~mW}$.

\section{Discussion}

Depositing multiple skin depths of copper on stainless-steel waveguides reduces losses up to $50 \%$ at the desired frequencies between 94 to $282 \mathrm{GHz}$. The plated waveguide offers a wide low-loss transmission bandwidth and is primarily limited by its cut-off frequency. The higher electric conductivity of copper, lower cost and efficient plating conditions promoted its use over gold $\left(\sigma_{\mathrm{Au}}=4.1 \times 10^{7}\right)$ as a plating metal. Often gold is favored for plating in electrical or chemical applications due to its superior resistance to corrosion. As such, waveguide attenuation and plate degradation were monitored across a period of 12 months after plating. Waveguide attenuation throughout the duration experienced no change, and the copper layer remained smooth and shiny (although no longer bright pink) while stored at room temperature in approx. $25-30 \%$ humidity. Furthermore, the installed waveguide performance remained consistent for at least 6 months of DNP testing, while experiencing thermal cycling and water condensation (on the outside) caused by probe withdrawal from the VTI. Waveguide bench measurements yield approx. $0.5 \mathrm{~dB}$ higher attenuation than theoretically calculated. This is due to misalignment in the measuring apparatus as well as resilient surface roughness.

Neat $\left[1-{ }^{13} \mathrm{C}\right]$ pyruvic acid doped with trityl radical is a well-established efficient sample for dDNP at the traditional 3.35 $\mathrm{T}$ field strength, as well at higher fields 4.6-7 $\mathrm{T}$ [6,20-22]. This behavior is primarily due to trityl's narrow ESR line spectrum compared to nitroxyl radicals (e.g. TEMPOL). The enhancement profile in Figure 7 a shows that the trityl radical is efficiently saturated even at low powers in all microwave configurations. The more efficient microwave delivery with the copperplated waveguide stems out clearly, when working at high power. Beyond $25 \mathrm{~mW}$ the DNP enhancement decreases due to excessive heating of the VTI. The effect is most prevalent when irradiating with maximum power $(55 \mathrm{~mW})$, the sample space temperature and VTI pressure promptly rise by $0.12 \pm 0.01 \mathrm{~K}$ to $1.32 \pm 0.01 \mathrm{~K}$. In such regime, relaxation times are shortened causing less efficient DNP and lower nuclear polarization. Moreover, heating the sample also yields faster build-up times due to accelerated relaxation processes at higher temperature (see Figure $7 \mathrm{~b}$ ). Observing the enhancement profile of all microwave configurations, it is evident that optimum irradiation power is inversely proportional to the microwave field density across the sample.

TEMPOL's ESR line width is approx. 5-6 times wider than trityl. Low power levels partially saturate the electron transitions resulting in suboptimal polarization as illustrated in Figure 8a. increased 
power levels remedy this limitation for all microwave configurations. However, the effect of heating at higher power levels is suppressed for this sample. At maximum power using a copper plated waveguide, $15 \%$ of maximum polarization is lost, a notable contrast to the $50 \%$ observed in the former sample. Build-up time constants in Figure $8 \mathrm{~b}$ converge and plateau for increased power levels, thus indicating less sensitivity to the heating by microwave absorption (resonant by the electron spins in the sample and non-resonant in the metallic structures).

Overall this behavior is attributed to the two competing mechanisms of heating and electron Zeeman transition saturation. Increasing the power level causes greater saturation that in turn promotes spectral diffusion across the ESR line. Rising the temperature due to heating accelerates spin-lattice relaxation making saturation more difficult. All DNP experiments in this study featured continuous microwave irradiation at a constant power level. The main advantage of more delivered microwave power is the ability to vary power levels in favor of higher build-up rates, thereby accelerating the polarization process.

The copper plated waveguide reduced resistive attenuation by $3.2 \mathrm{~dB}$ at $188 \mathrm{GHz}$. In turn, the average $\mathrm{H}$-field across the sample volume is expected to increases by a factor of approx. $42 \%$, which is in good agreement with the $\sim 45 \%$ decrease in build-up time at any given microwave power level. As for the augmented cavity, EM simulations estimated a 2.85 factor increase in field density, which is the equivalent of boosting the microwave source power by $9.1 \mathrm{~dB}$. However, the measured $\sim 30 \%$ reduction in build-up time suggests a $2.3 \mathrm{~dB}$ equivalent improvement in microwave power delivery. The difference between theory and experiment can most likely be attributed to unaccounted scattering in practice, making the power distribution more even and favorable without the reflector. Likewise, the reflector may not direct the microwave as focused to the sample and demonstrated by simulation, e.g. due to losses or geometrical imperfections.

Good agreement is obtained between the calculated and experimentally verified heat load values. Indeed, the computed thermal model could have incorporated other forms of heat transfer and cooling from rising helium gas but not without significant numerical complexity. The demonstrated method is valuable for thermal budgeting during dDNP probe design, even when utilizing a simplified model.

\section{Conclusion}

We studied different methods for improving microwave delivery and irradiation of the electron spins whilst improving maximum nuclear polarization and reducing build-up times. Overmoded circular waveguides offer a better thermal conduction to attenuation ratio than rectangular waveguides. An electroplating process with copper is detailed to reduce attenuation in a stainless-steel waveguide 
by half. Additionally, a solution to increase microwave field density across the sample volume using a mirror and segmented reflector in the cavity was designed, simulated, and tested. The addition of the mirror did not perturb the coil homogeneity, while the reflector reduced the coil Q-factor from 355 to 342.

Improvements in microwave delivery and irradiation were tested using two samples employing trityl and TEMPOL radicals in DNP experiments. Use of a copper plated waveguide approx. doubles the delivered microwave power to the sample. While inclusion of an augmented cavity resulted in approx. $2.3 \mathrm{~dB}$ increase in equivalent microwave power. The dDNP probe heat load reduces from $1070 \mathrm{~mW}$ with a copper waveguide to $224 \mathrm{~mW}$ with a stainless-steel waveguide. When considering the latter, the coaxial cable is the dominant heat load and contributes $141 \mathrm{~mW}$ of which the inner conductor accounts for $130 \mathrm{~mW}$.

\section{Acknowledgement}

The authors would like to thank and acknowledge Jan Kilund and Jan Raagaard Petersen from the Centre for Hyperpolarization in Magnetic Resonance (HYPERMAG) at DTU for their technical support. This work is supported by the European Union's Horizon 2020 research and innovation program under the Marie Sklodowska-Curie grant agreement No. 642773 and the Danish National Research Foundation (DNRF124). 


\section{References}

[1] J.H. Ardenkjaer-Larsen, B. Fridlund, A. Gram, G. Hansson, L. Hansson, M.H. Lerche, R. Servin, M. Thaning, K. Golman, Increase in signal-to-noise ratio of $>10,000$ times in liquidstate NMR, Proc. Natl. Acad. Sci. 100 (2003) 10158-10163. doi:10.1073/pnas.1733835100.

[2] S.J. Nelson, J. Kurhanewicz, D.B. Vigneron, P.E.Z. Larson, A.L. Harzstark, M. Ferrone, M. van Criekinge, J.W. Chang, R. Bok, I. Park, G. Reed, L. Carvajal, E.J. Small, P. Munster, V.K. Weinberg, J.H. Ardenkjaer-Larsen, A.P. Chen, R.E. Hurd, L.-I. Odegardstuen, F.J. Robb, J. Tropp, J.A. Murray, Metabolic Imaging of Patients with Prostate Cancer Using Hyperpolarized [1-13C]Pyruvate, Sci. Transl. Med. 5 (2013) 198ra108-198ra108. doi:10.1126/scitransImed.3006070.

[3] J. Kurhanewicz, D.B. Vigneron, J.H. Ardenkjaer-Larsen, J.A. Bankson, K. Brindle, C.H. Cunningham, F.A. Gallagher, K.R. Keshari, A. Kjaer, C. Laustsen, D.A. Mankoff, M.E. Merritt, S.J. Nelson, J.M. Pauly, P. Lee, S. Ronen, D.J. Tyler, S.S. Rajan, D.M. Spielman, L. Wald, X. Zhang, C.R. Malloy, R. Rizi, Hyperpolarized 13C MRI: Path to Clinical Translation in Oncology, Neoplasia. 21 (2019) 1-16. doi:10.1016/j.neo.2018.09.006.

[4] M. Batel, M. Krajewski, A. Däpp, A. Hunkeler, B.H. Meier, S. Kozerke, M. Ernst, Dissolution dynamic nuclear polarization efficiency enhanced by Hartmann-Hahn cross polarization, Chem. Phys. Lett. 554 (2012) 72-76. doi:10.1016/j.cplett.2012.10.018.

[5] A. Comment, B. van den Brandt, K. Uffmann, F. Kurdzesau, S. Jannin, J.A. Konter, P. Hautle, W.T. Wenckebach, R. Gruetter, J.J. van der Klink, Principles of Operation of a DNP Prepolarizer Coupled to a Rodent MRI Scanner, Appl. Magn. Reson. 34 (2008) 313-319. doi:10.1007/s00723-008-0119-3.

[6] J.H. Ardenkjaer-Larsen, S. Bowen, J.R. Petersen, O. Rybalko, M.S. Vinding, M. Ullisch, N.C. Nielsen, Cryogen-free dissolution dynamic nuclear polarization polarizer operating at 3.35 T, 6.70 T, and 10.1 T, Magn. Reson. Med. 81 (2019) 2184-2194. doi:10.1002/mrm.27537.

[7] M. Baudin, B. Vuichoud, A. Bornet, G. Bodenhausen, S. Jannin, A cryogen-consumptionfree system for dynamic nuclear polarization at 9.4 T, J. Magn. Reson. 294 (2018) 115-121. doi:10.1016/j.jmr.2018.07.001.

[8] D. Pozar, Microwave engineering, Fourth ed., John Wiley \& Sons, Inc., Hoboken, NJ, 2012.

[9] A. Rybalko, S. Rubets, E. Rudavskii, V. Tikhiy, S. Tarapov, R. Golovashchenko, V. Derkach, Resonance absorption of microwaves in He II: Evidence for roton emission, Phys. Rev. B - 
Condens. Matter Mater. Phys. (2007). doi:10.1103/PhysRevB.76.140503.

[10] J.H. Ardenkjaer-Larsen, A.M. Leach, N. Clarke, J. Urbahn, D. Anderson, T.W. Skloss, Dynamic nuclear polarization polarizer for sterile use intent, NMR Biomed. 24 (2011) $927-$ 932. doi:10.1002/nbm.1682.

[11] I. Rajagopal, K.S. Rajam, S.R. Rajagopalan, Gold plating of critical components for space applications: Challenges and solutions, Gold Bull. 25 (1992) 55-66. doi:10.1007/BF03214720.

[12] M. Batel, M. Krajewski, K. Weiss, O. With, A. Däpp, A. Hunkeler, M. Gimersky, K.P. Pruessmann, P. Boesiger, B.H. Meier, S. Kozerke, M. Ernst, A multi-sample $94 \mathrm{GHz}$ dissolution dynamic-nuclear-polarization system, J. Magn. Reson. 214 (2012) 166-174. doi:10.1016/j.jmr.2011.11.002.

[13] M. Rosay, M. Blank, F. Engelke, Instrumentation for solid-state dynamic nuclear polarization with magic angle spinning NMR, J. Magn. Reson. 264 (2016) 88-98. doi:10.1016/j.jmr.2015.12.026.

[14] A. Purea, B. Ell, C. Reiter, F. Aussenac, F. Engelke, Augmenting microwave irradiation in MAS DNP NMR samples at 263 GHz, EPJ Web Conf. 187 (2018) 01005. doi:10.1051/epjconf/201818701005.

[15] J. Milani, B. Vuichoud, A. Bornet, R. Melzi, S. Jannin, G. Bodenhausen, Hyperpolarization of nitrogen-15 nuclei by cross polarization and dissolution dynamic nuclear polarization, Rev. Sci. Instrum. 88 (2017) 015109. doi:10.1063/1.4973777.

[16] E.A. Nanni, A.B. Barnes, Y. Matsuki, P.P. Woskov, B. Corzilius, R.G. Griffin, R.J. Temkin, Microwave field distribution in a magic angle spinning dynamic nuclear polarization NMR probe, J. Magn. Reson. 210 (2011) 16-23. doi:10.1016/j.jmr.2011.02.001.

[17] S.C. Michelson, S. Evans, Dielectric properties of supercooled cryoprotectant agents, Phys. Med. Biol. 41 (1996) 2053-2066. doi:10.1088/0031-9155/41/10/014.

[18] National Institute of Standards Technology, Material Properties, US Dep. Commer. (2012). https://trc.nist.gov/cryogenics/materials/materialproperties.htm.

[19] A. Capozzi, M. Karlsson, J.R. Petersen, M.H. Lerche, J.H. Ardenkjaer-Larsen, Liquid-State 13C Polarization of $30 \%$ through Photoinduced Nonpersistent Radicals, J. Phys. Chem. C. 122 (2018) 7432-7443. doi:10.1021/acs.jpcc.8b01482.

[20] H. Jóhannesson, S. Macholl, J.H. Ardenkjaer-Larsen, Dynamic Nuclear Polarization of [113C]pyruvic acid at 4.6 tesla, J. Magn. Reson. 197 (2009) 167-175. 
doi:10.1016/j.jmr.2008.12.016.

[21] H.A.I. Yoshihara, E. Can, M. Karlsson, M.H. Lerche, J. Schwitter, A. Comment, High-field dissolution dynamic nuclear polarization of [1-13 C]pyruvic acid, Phys. Chem. Chem. Phys. 18 (2016) 12409-12413. doi:10.1039/C6CP00589F.

[22] F. Jähnig, G. Kwiatkowski, A. Däpp, A. Hunkeler, B.H. Meier, S. Kozerke, M. Ernst, Dissolution DNP using trityl radicals at 7 T field, Phys. Chem. Chem. Phys. (2017). doi:10.1039/c7cp03633g.

[23] W.T. Wenckebach, Spectral diffusion and dynamic nuclear polarization: Beyond the high temperature approximation, J. Magn. Reson. 284 (2017) 104-114. doi:10.1016/j.jmr.2017.10.001. 


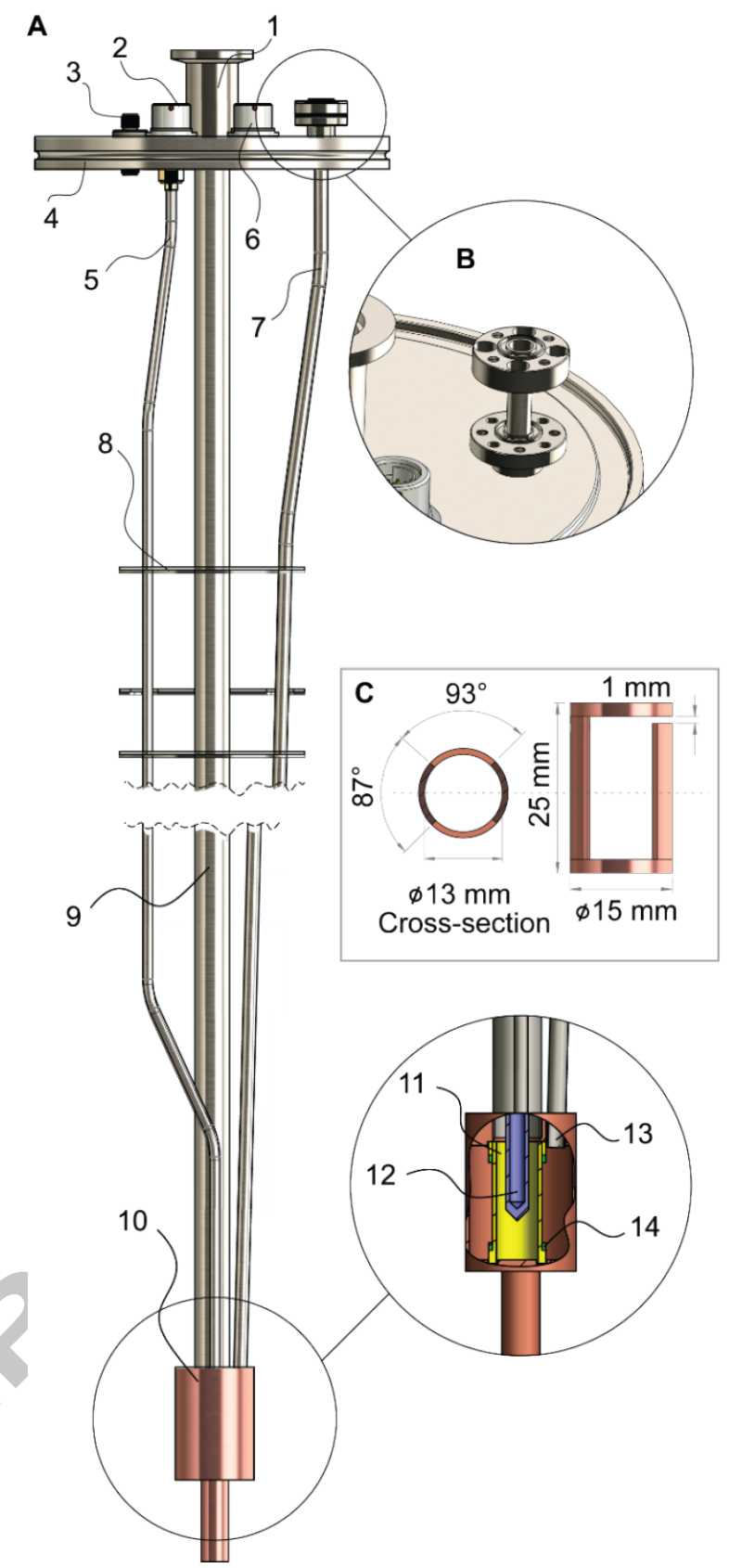

Figure 1: (a) dDNP probe drawing. 1.sample loading port, 2. helium level connector, 3. hepatic SMA connector, 4. ISO-F100 flange, 5. UT141SS-C-P coaxial cable, 6. thermometer connector, 7. waveguide, 8. baffles, 9. sample tube, 10. overmoded cavity, 11. PTFE coil former, 12. sample vial (purple), 13. waveguide outlet, 14. Alderman-Grant sample coil (green). Not illustrated: AllenBradley resistors, Cernox sensor and second SMA connector (positioned behind component 2.). (b) Modified UG387 waveguide flange and coupling flange. (c) Geometry of Alderman-Grant sample coil. 


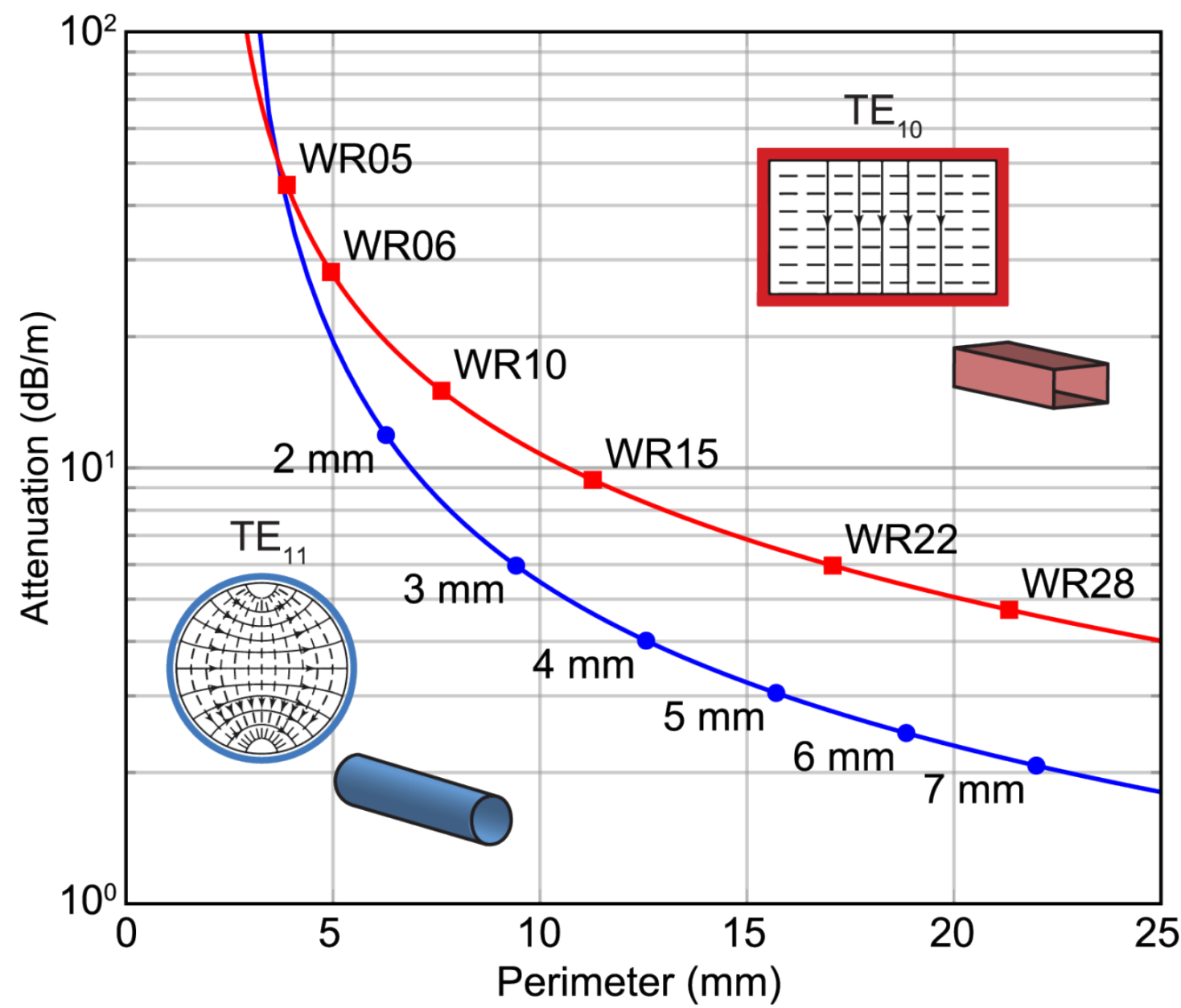

Figure 2: Theoretical ohmic attenuation vs. cross-section perimeter of rectangular $\left(\mathrm{TE}_{10}\right)$ and circular $\left(\mathrm{TE}_{11}\right)$ stainless-steel waveguides at $188 \mathrm{GHz}$. Standard WR designations indicated by ( $\square$ ) while circular diameters in $1 \mathrm{~mm}$ increment indicated by $(\bullet)$. 

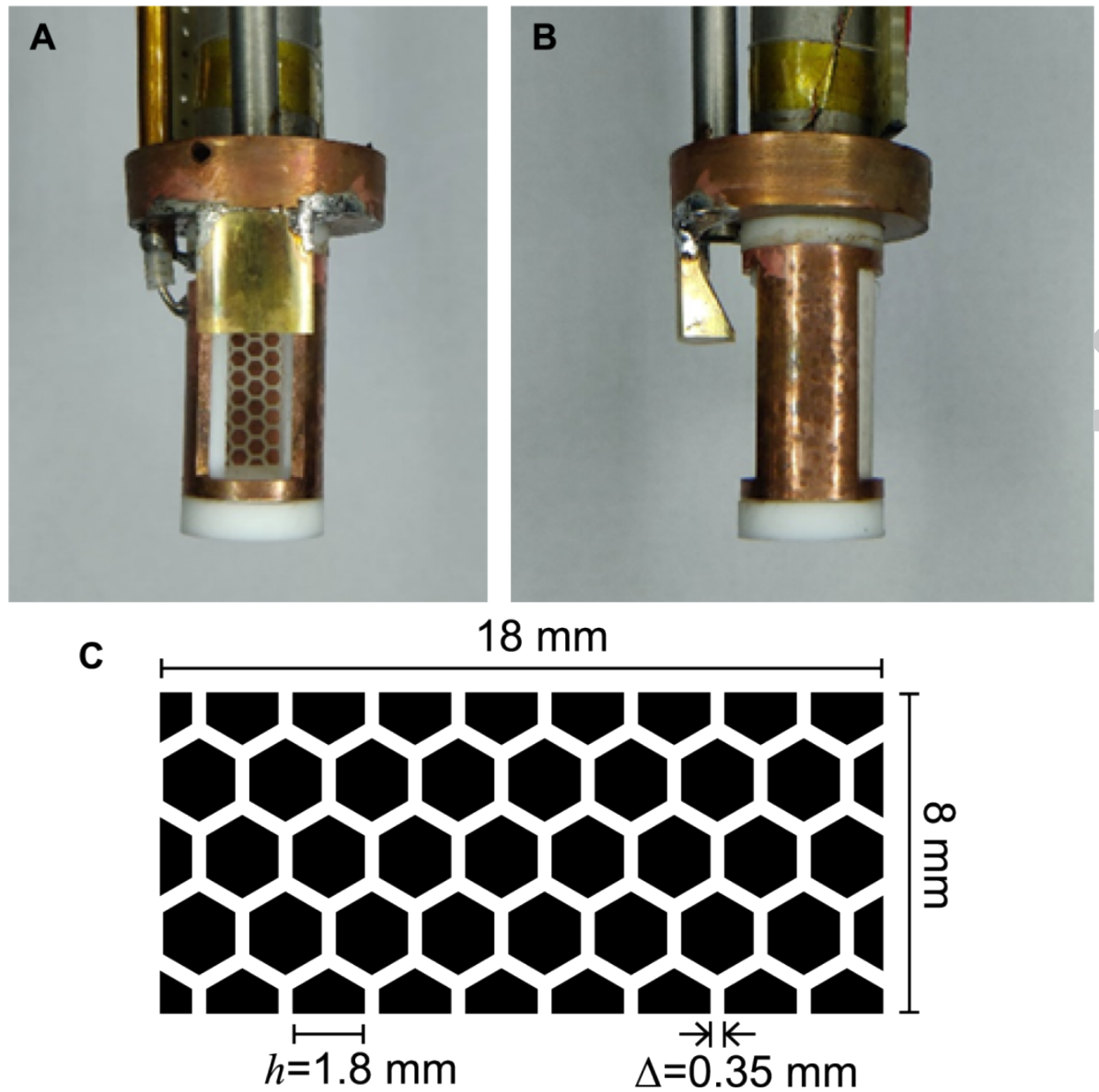

Figure 3: (a) Photograph of the augmented cavity (copper can removed) with Alderman-Grant coil, brass mirror and segmented reflector. (b) The reflector fully covers the coil opening and is held in place by the coil and coil former. 


\begin{tabular}{|c|c|c|c|}
\hline Component & Material & Cross section $\left(\mathrm{mm}^{2}\right)$ & $\begin{array}{l}\text { Conductive heat flux } \\
(\mathrm{mW})\end{array}$ \\
\hline Sample tube & 316L stainless-steel & 17.32 & 66 \\
\hline $\begin{array}{l}\text { Coaxial } \\
\text { transmission line } \\
(\mathrm{UT} 141-\mathrm{SS}-\mathrm{C}-\mathrm{P})\end{array}$ & $\begin{array}{l}\text { 316L stainless-steel, } \\
\text { copper, PTFE }\end{array}$ & 10.07 & $141^{*}$ \\
\hline Waveguide & $\begin{array}{l}304 \text { stainless-steel } \\
\text { (copper plated) }\end{array}$ & 4.24 & \\
\hline Waveguide & Copper & 4.24 & 847 \\
\hline
\end{tabular}

Table 1: Conductive heat flux across dDNP probe at steady state conditions, $\mathrm{T}_{\text {ambient }}=300 \mathrm{~K}$ and $\mathrm{T}_{\text {probe }}=4 \mathrm{~K}(\Delta T=296 \mathrm{~K})$ as computed by COMSOL Multiphysics ${ }^{\circledR} .{ }^{*}$ Outer conductor: $11 \mathrm{~mW}$, Inner conductor: $130 \mathrm{~mW}$.

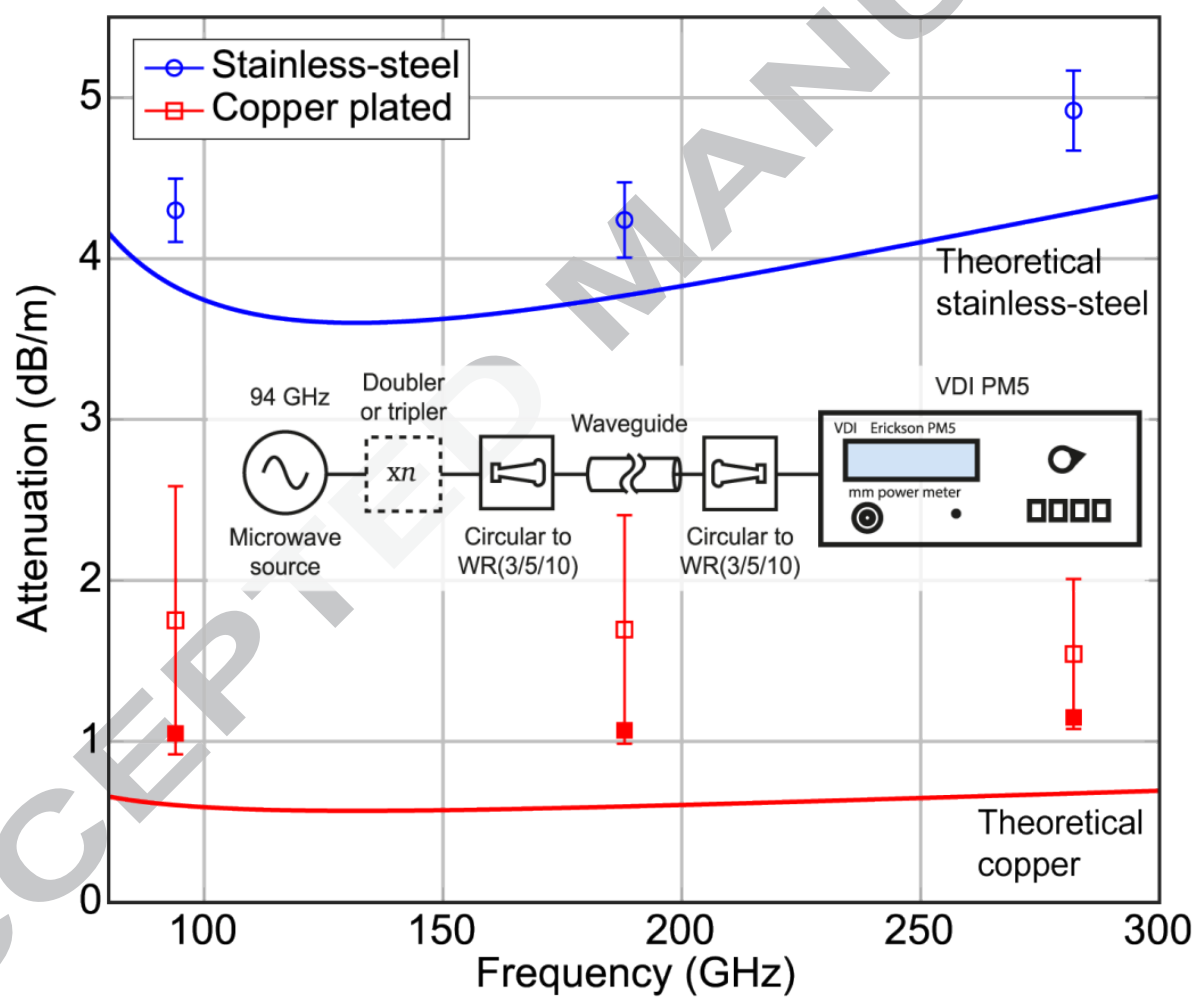

Figure 4: Theoretical microwave attenuation in circular a stainless-steel and copper waveguides ( $\mathrm{TE}_{11}$, $\left.r=2.08 \pm 0.02 \mathrm{~mm}, p_{11}=1.841\right)$ including bench measurement for stainless-steel (०) and copper plated $(\square)$ waveguides and attenuation of copper plated waveguide used in dDNP probe ( $\mathbf{\square})$. 

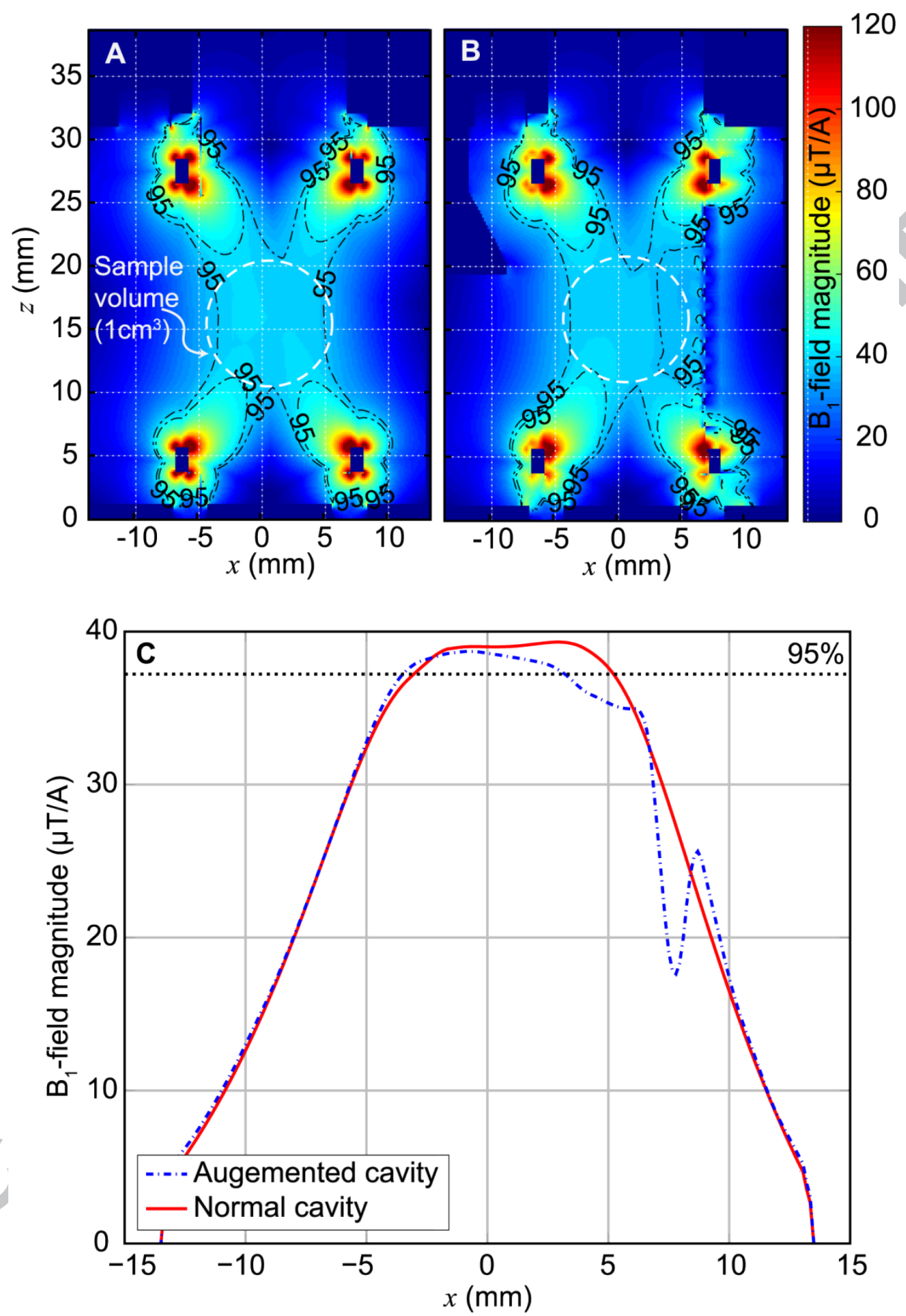

Figure 5: Simulated $\mathrm{B}_{1}$-field at $71.8 \mathrm{MHz}$ across coil isocenter for a cavity (a) without and (b) with augmentation. (c) 1D $B_{1}$-field variation across the cut plane, dotted line signifies $95 \%$ field homogeneity. 

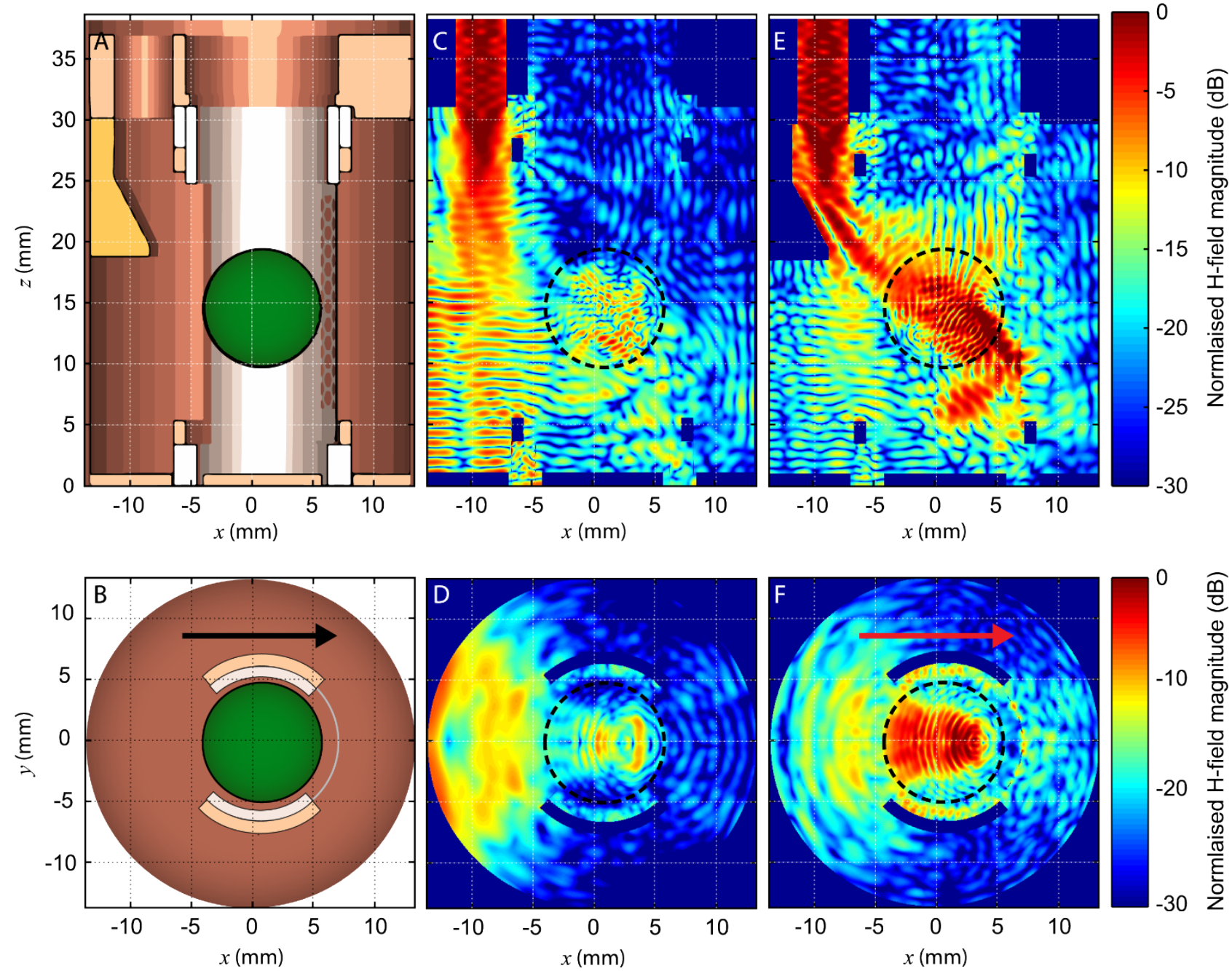

Figure 6: Simulated time averaged $\mathrm{H}$-field at $188 \mathrm{GHz}$. Field normalized with respect to maximum field intensity inside the waveguide. Upper row figures refer to cross-section at $x=0$, with the bottom row at $z=18$. (a) \& (b) illustration of an augmented cavity, (b) and (d) time averaged $\mathrm{H}$-field in a cavity, (e) \& (f) time averaged $\mathrm{H}$-field in an augmented cavity. Arrow indicating direction of propagation of reflected waves. 

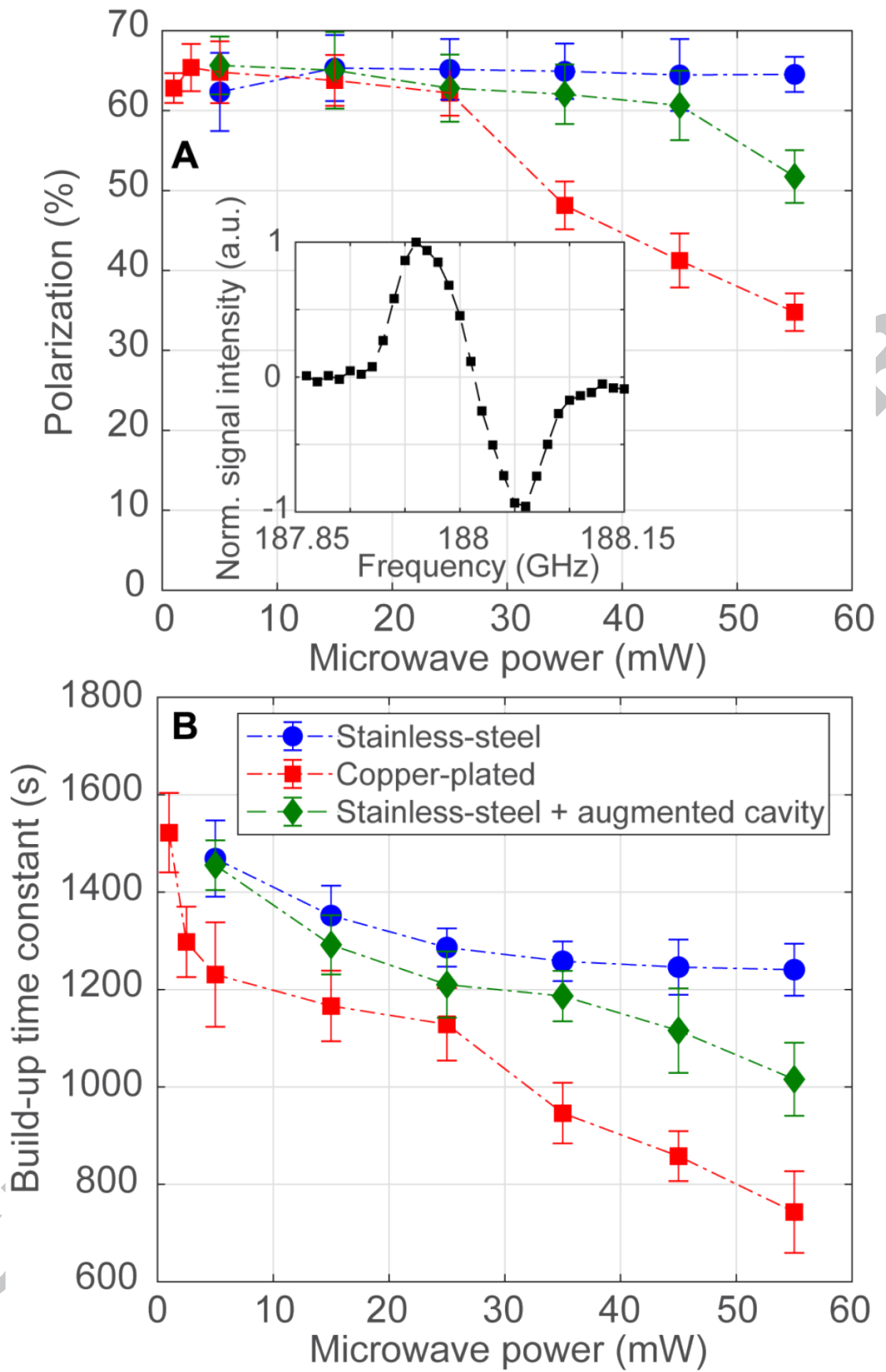

Figure 7: (a) Polarization and (b) build-up time constants $\left(\tau_{b}\right)$ for $50 \mu \mathrm{L} 14 \mathrm{M}\left[1-{ }^{13} \mathrm{C}\right]$ pyruvic acid

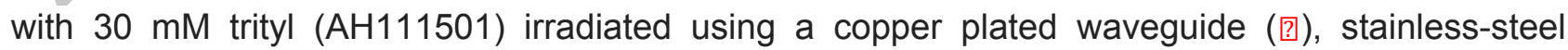
waveguide $(\bullet)$, and stainless-steel waveguide with mirror and reflector $(\diamond)$. Inset graph illustrates the normalized DNP profile of the sample. 

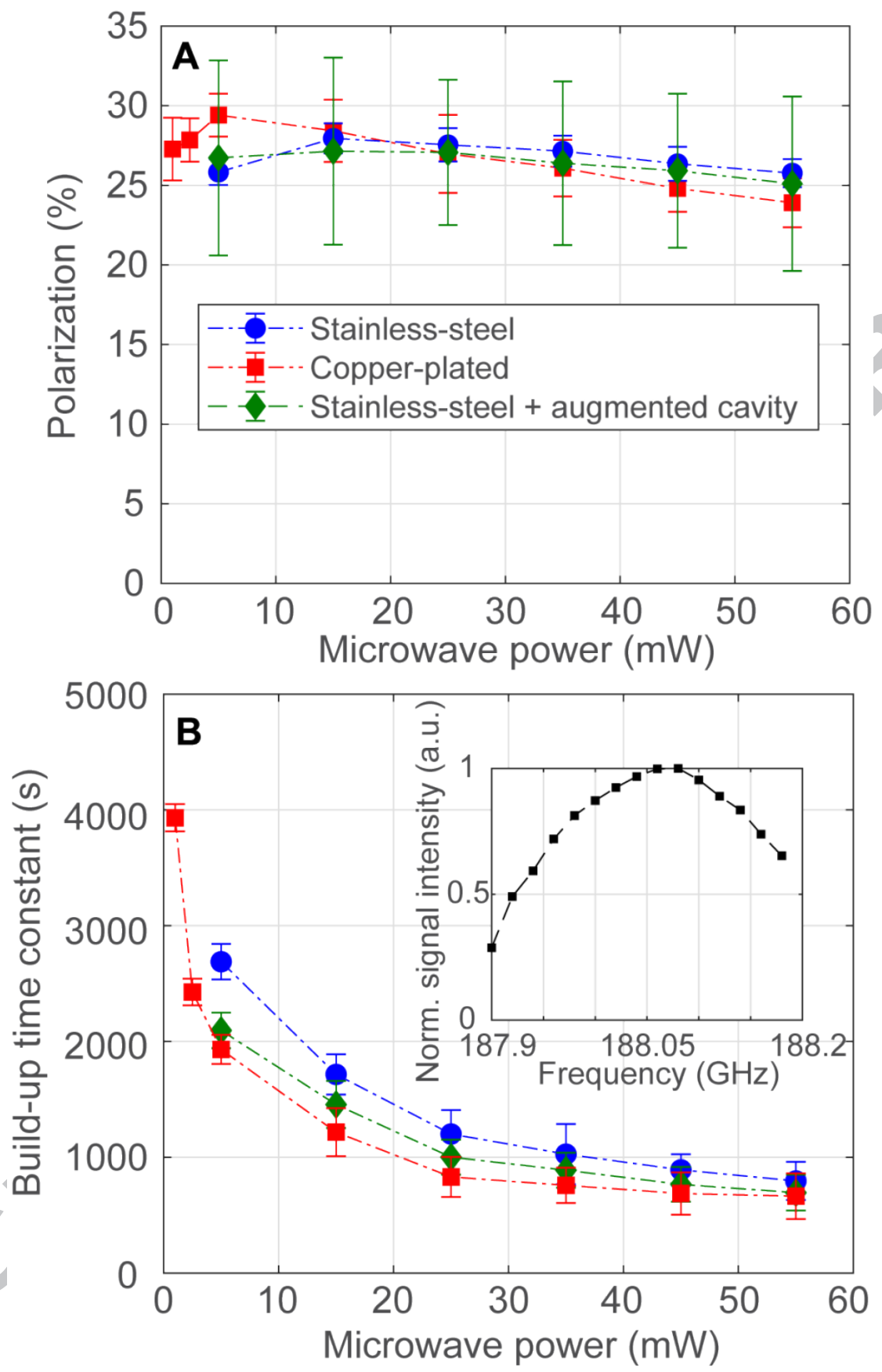

Figure 8: (a) Polarization and (b) build-up time constants $\left(\tau_{b}\right)$ for $100 \mu \mathrm{L} 4.5 \mathrm{M}\left[1-{ }^{13} \mathrm{C}\right] \mathrm{urea}$ dissolved in $\mathrm{d}_{8}$-glycerol and $\mathrm{D}_{2} \mathrm{O}(50: 50 \mathrm{v} / \mathrm{v})$ with $40 \mathrm{mM}$ TEMPOL irradiated using a copper plated waveguide (回), stainless-steel waveguide $(\bullet)$, and stainless-steel waveguide with mirror and reflector $(\diamond)$. Inset graph illustrates the normalized DNP profile of the sample. 
Graphical abstract
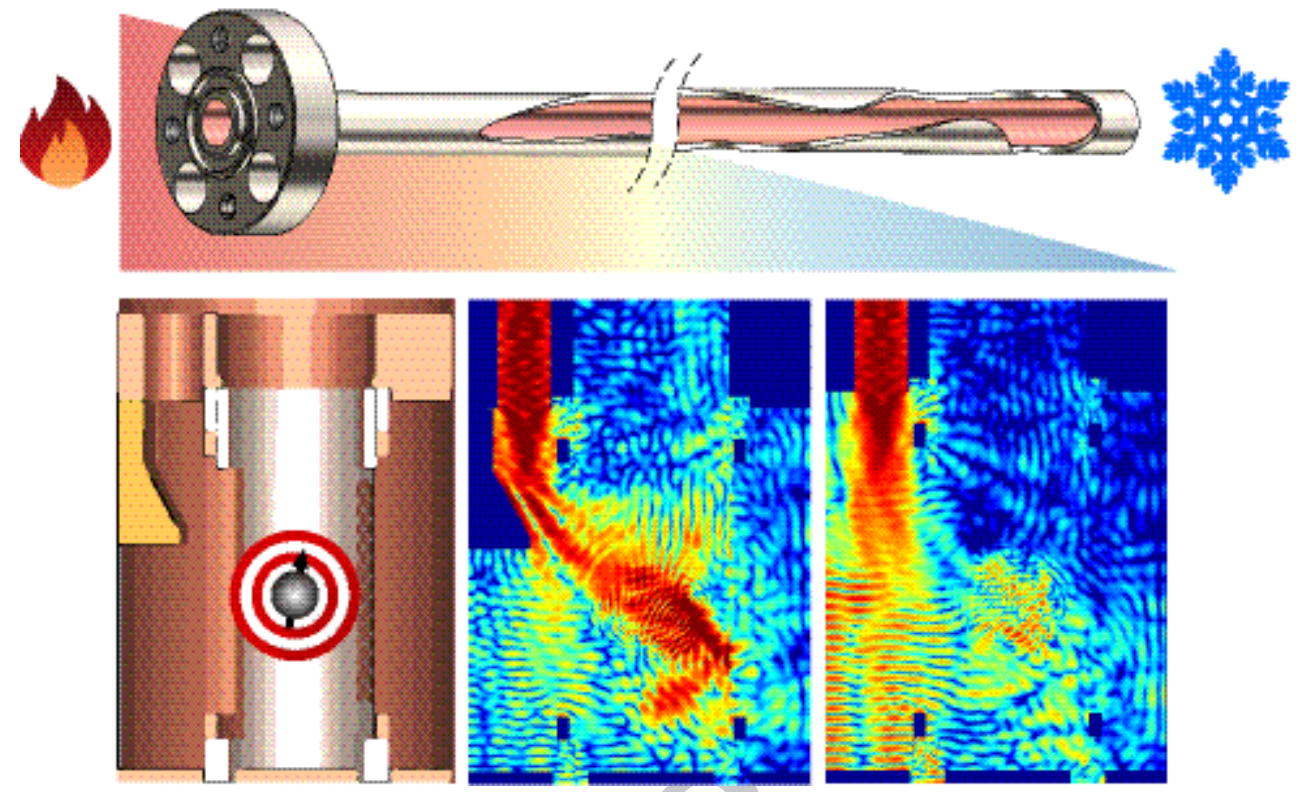


\section{Highlights}

- Microwave delivery to the electron spins are doubled by with use of copper plated waveguide.

- Design and fabrication of mirror and reflector to support higher microwave field density across sample volume.

- Experimentally verified thermal model for designing probe for dDNP. 